\title{
ALTRUISM, FERTILITY, AND THE VALUE OF CHILDREN: HEALTH POLICY EVALUATION AND INTERGENERATIONAL WELFARE
}

\author{
Javier A. Birchenall \\ Rodrigo R. Soares \\ Working Paper 12836 \\ http://www.nber.org/papers/w12836 \\ NATIONAL BUREAU OF ECONOMIC RESEARCH \\ 1050 Massachusetts Avenue \\ Cambridge, MA 02138 \\ January 2007
}

Previous versions of this paper circulated under the title "Fertility and the Value of Life." We owe special thanks to Maureen Cropper for important suggestions. We also benefited from comments from Ted Bergstrom, Roger Betancourt, Kevin Frick, Robin Jenkins, Michael Manove, Esteban Rossi-Hansberg, Seth Sanders, and seminar participants at EPGE-FGV, PUC-Rio, Universidad Nacional (Bogota), University of Maryland, USP, and the 2006 Latin American Meeting of the Econometric Society (Mexico City). Soares gratefully acknowledges financial support from the Conselho Nacional de Pesquisa e Desenvolvimento Tecnologico (CNPq), Brazil. The views expressed herein are those of the author(s) and do not necessarily reflect the views of the National Bureau of Economic Research.

(C) 2007 by Javier A. Birchenall and Rodrigo R. Soares. All rights reserved. Short sections of text, not to exceed two paragraphs, may be quoted without explicit permission provided that full credit, including $(\odot$ notice, is given to the source. 
Altruism, Fertility, and the Value of Children: Health Policy Evaluation and Intergenerational

Welfare

Javier A. Birchenall and Rodrigo R. Soares

NBER Working Paper No. 12836

January 2007

JEL No. I10,J13,J17

\section{ABSTRACT}

This paper accounts for the value of children and future generations in the evaluation of health policies. This is achieved through the incorporation of altruism and fertility in "value of life" type of framework. We are able to express adults' willingness to pay for changes in child mortality and also to incorporate the welfare of future generations in the evaluation of current policies. Our model clarifies a series of puzzles from the literature on the "value of life" and on intergenerational welfare comparisons. We show that, by incorporating altruism and fertility into the analysis, the estimated welfare gain from recent reductions in mortality in the U.S. easily doubles.

Javier A. Birchenall

Department of Economics

University of California

2127 North Hall

Santa Barbara, CA 93106

jabirche@econ.ucsb.edu

Rodrigo R. Soares

Department of Economics

University of Maryland

3105 Tydings Hall

College Park, MD 20742

and NBER

soares@econ.umd.edu 


\section{Introduction}

This paper accounts for the value of children and future generations in the evaluation of health policies. This is achieved through the incorporation of altruism and fertility in a "value of life" type of framework. We argue that altruism and fertility are natural ways to model the value that parents attach to children, which is intrinsically related to the value that present generations attach to the welfare of future generations. By bringing these new dimensions into the analysis, we are able to express adults' willingness to pay for changes in child mortality and also to incorporate the welfare of future generations in the evaluation of current policies. This is done in a setting where fertility, and therefore the size of future generations itself, is endogenous to current generations' decisions. Our model clarifies a series of puzzles from the literature on the "value of life" and on intergenerational welfare comparisons, ranging from the profile of the "value of a statistical life" over the life-cycle to the specific way in which individuals who have not yet been born-and whose existence itself may depend on current actions-should be incorporated in cost-benefit analyses.

An increasing body of literature has applied the "value of life" methodology to analyze different aspects of welfare gains from changes in mortality rates. ${ }^{1}$ These studies made important contributions to the understanding and measurement of non-monetary aspects of human welfare. Yet they suffer from an important methodological drawback: they do not incorporate in the analysis altruism, fertility decisions, and their consequences in terms of welfare evaluation. Two interrelated dimensions of fertility choice are essential in evaluating life expectancy and health-related welfare gains. First, child mortality rates-which would be irrelevant for the welfare of an adult individual in an egoistic setup-can be very important in determining welfare in a context in which individuals choose the number of children they have. Second, if altruism motivates fertility, life expectancy gains have a twofold effect: they directly increase utility via increased survival probabilities, and they increase utility via the increased welfare of the offspring. ${ }^{2}$

\footnotetext{
1 The main contributions to the theoretical literature were made by Schelling (1968), Usher (1973), Arthur (1981), and Rosen (1988, 1994), among others. Nordhaus (2003), Murphy and Topel (2003), and Garrett (2001) applied this methodology to analyze different aspects of health-related gains in welfare in the United States throughout the twentieth century. Philipson and Soares (2005) used this methodology to estimate the income value of the welfare loss due to AIDS in sub-Saharan Africa, while Soares (2006) applied this methodology to estimate the welfare cost of violence across different regions of the world. Becker, Philipson, and Soares (2005) applied an adapted version of the same technique to evaluate the evolution of welfare inequality across countries, once improvements in life expectancy are accounted for. Becker and Elias (2006) use estimates from the "value of life" to infer how much it would cost to increase sufficiently the supply of organs for live transplants in order to eliminate any significant waiting time.

2 Cropper and Sussman (1988) and Rosen (1994) consider the problem of marginal willingness to pay for reductions in mortality rates when individuals leave bequests to a single descendant. Under certain circumstances, this may correspond to the incorporation of altruism. Some of the recent literature cited above tries to incorporate future populations by extending discount or interest rates across different generations. In general, intergenerational discount is different from time discount, so these should not be treated as being the same concept. One cannot extrapolate what one individual does over the lifetime to different individuals. In any case, none of these papers
} 
In this paper, we evaluate the welfare implications of mortality reductions in a setup in which individuals choose the number of children they have and are altruistic toward their children. We show that, under these circumstances, the value of adult mortality changes can be decomposed into three factors: the consumption factor from the traditional "value of life" specification, discussed in Rosen (1988); a fertility factor, which accounts for the welfare improvements related to the higher probability of having children; and an altruism factor, which accounts for the fact that mortality reductions will also be enjoyed by all future generations. In addition, our approach allows us to calculate an adult's willingness to pay for reductions in child mortality. This willingness to pay generally depends on the effect of child mortality on the final costs of child production, the uncertainty regarding the number of surviving children, and the emotional loss associated with the death of a child. As in the case of adult mortality, child mortality reductions are also valued because future generations will benefit from it. In fact, we show that, when parents care for their children through altruistic links, any marginal willingness to pay approach that adequately accounts for parents' preferences will also account for the value of welfare gains to future generations.

In order to illustrate the relevance of the new dimensions introduced by our theoretical framework, we calibrate our model to U.S. data and calculate the value that the population alive in 1965 would attribute to the mortality reductions observed between 1965 and 1995 . Our results imply that the welfare gain for an 18-year-old individual is between $79 \%$ and $200 \%$ higher than what would have been estimated if the welfare that young adults derive from their children was ignored. The aggregate social value is between $27 \%$ and $80 \%$ higher. These differences are due to benefits from child mortality reductions that are enjoyed by young adults and that could not have been estimated had we not incorporated altruism and fertility in the analysis. In addition, our calibrated model generates as by-products some curious numbers, never before estimated in the literature. For example, a function of parameters that can be roughly understood as the monetary value of the emotional loss from the death of a child is estimated to be between $\$ 1.2$ million and $\$ 3.9$ million.

Though applied to the analysis of changes in health, the paper touches on the more general question of how to deal with children and future generations in the evaluation of policy interventions. Since mortality risk at any age is a completely forward-looking measure, egoistic adults who survive childhood place zero value on mortality changes at earlier ages. As a consequence, in the standard framework, the contribution of changes in child mortality to the welfare of an adult is null, since altruistic behavior toward offspring is not taken into account. In reality, however,

include the choice of number of children together with the value that parents attach to children, and therefore cannot be extended to adequately account for future generations. 
future generations cannot voice their concerns or reveal their preferences via market behavior, and children, because of lack of maturity and dependence on parental care, are incapable of legally deciding. For these same reasons, contractual arrangements involving children-or possibly unborn individuals-cannot directly incorporate future benefits in current evaluations of policy interventions (see the discussion in Becker and Murphy, 1988). As an alternative, our model allows for endogenous fertility and altruism in order to transfer the benefits of certain policies across different generations. In our theory, as in reality, parents are the ones who decide and are liable for their children.

Altruism in human societies is certainly not restricted to the immediate family or even to direct descendants. Nevertheless, the case for incorporating parents' altruism toward children in public policy evaluation seems far stronger than any other. ${ }^{3}$ Not only does this approach incorporate the preferences of a significant share of the population that is not allowed to decide (children), but it also establishes an intergenerational link that ultimately accounts for the benefits accrued by all future generations. In addition, the task of assigning values to welfare gains experienced by children is transferred to those who are the children's legal guardians and already decide for them in all relevant dimensions of life, namely, the parents.

Several applications have stressed that the evaluation of policies affecting children requires knowledge of parental preferences, since children are not the actual decision-makers in most legal and economic contexts (see, for example, Carlin and Sandy, 1991, Mount et al., 2000, Dickie and Ulery, 2001, and Jenkins, Owens, and Wiggins, 2001). Endogenous fertility decisions have also been suggested as a way to deal with evaluations of welfare involving future generations, since exogenous fertility implies a series of puzzling considerations. Under exogenous fertility, an unrestricted number of births is always advocated because it increases the aggregate number of years lived in society and, hence, social welfare. Also, changes in mortality immediately before or after birth cannot be adequately taken into account, since there are almost no expenditures undertaken by parents up to that point. As a consequence, there is no theoretical basis to determine how unborn individuals should be treated (see Preston, 1993, Deaton, 2004, and Viscusi, 2005). ${ }^{4}$

\footnotetext{
${ }^{3}$ Bergstrom $(1982,2006)$ and Jones-Lee (1992) study altruism within the family and its effects on the value of life, but with no considerations for costly fertility decisions. Bergstrom (1982) shows that "pure altruism" produces no additional value for changes in health risks if altruistic concerns are dealt with in the first order condition. Jones-Lee (1992) provides several extensions and generalizations. The case of fertility poses different problems because, in a marriage, as studied for example in Bergstrom (2006), the utility functions of husband and wife are well-defined and the formation of a marriage is voluntary. Not only are children self-produced by parents, but unborn children's self-valuation is not observable nor contractable.

${ }^{4}$ Valuations made by nineteenth-century courts after wrongful deaths of children were given in terms of replacement of children's lost wages but became unfounded when child labor was abolished (Zelizer, 1994). Valuations in terms of parental investments in the upbringing of a child are also contradictory, especially for very young children, because, as Zelizer (1994, p.135) notes, they "would lead to the awkward conclusion that the average child had a negative worth and its death was a benefit for parents."
} 
Our framework shows that these puzzling considerations arise because altruism and fertility decisions are absent from traditional models. Once altruism and fertility are incorporated in the analysis-and an endogenous link between parents and children is established-the problems disappear. Generally, the same principle explored here can be extended to any other policy context in which government interventions have their costs or benefits spread out through different generations.

The structure of the remainder of the paper is outlined as follows. Section 2 presents a simple model illustrating the main implications of the incorporation of fertility and altruism into "value of life" calculations. Section 3 develops the general version of the model, and derives a formula for the social value of changes in survival functions. Section 4 illustrates the empirical relevance of our approach by calculating the value of the mortality reductions experienced by the U.S. population between 1965 and 1995. Section 5 concludes the paper with some general remarks.

\section{A Simple Model of Fertility and the Value of Life}

This section illustrates the consequences of altruism and endogenous fertility for the valuation of life expectancy changes, and shows that they are intrinsically related to the value that parents attach to children and future generations. We construct a simplified example, as close as possible to the simplest model presented in Rosen (1988), in order to highlight the dimensions added to the problem and to compare our results to the previous literature.

Consider individuals who live for three periods: childhood, young adulthood, and mature adulthood. Individuals face a probability $p_{c}$ of surviving birth. If they survive birth, they become young adults and face a probability $p_{a}$ of survival into mature adulthood. Decisions are made at this stage, after individuals survive child mortality, and just before their adult mortality is realized. ${ }^{5}$ If individuals survive into mature adulthood, their consumption and fertility plans are carried out, and then their offspring face the child mortality risk.

At time $t$, young adults receive an endowment $w_{t}$. Young adults decide on consumption and number of births before the event with probability $p_{a}$ is realized. Actuarially fair insurance is available for every good consumed by parents, so that the budget constraint can be written as

\footnotetext{
5 Though this sequence of events may seem excessively artificial, it keeps things as simple as possible. The interpretation of the different stages becomes more natural in the generalized version of the model. For simplicity, we also ignore general equilibrium effects of changes in mortality and analyze an economy without production. With the exception of Arthur (1981), all papers in this literature have ignored general equilibrium implications. In Arthur (1981), however, all fertility decisions are exogenous. In our model, we address the economic value of changes in health that are outside the control of any particular individual (as related to scientific and technological developments in medical and biological sciences, for example). If households have control over some aspects of mortality, endogenous mortality changes will have no effect on welfare in addition to that reflected on expenditures.
} 


$$
w_{t}=p_{a}\left[c_{t}+n_{t} b+\left(p_{c} n_{t}\right) e\right]
$$

where $b$ is the goods cost of having a child and $e$ is the goods cost of raising a surviving child. The costs of having and raising children are assumed to be fixed. To keep things simple and comparable to the previous literature, we assume no margin in which parents can invest or transfer additional resources to their children. ${ }^{6}$

Adults value consumption, the number of surviving children they have, and the utility that each child will enjoy as an adult. Adults are responsible for all decisions in the economy. Figure 1 summarizes the sequence of events in this simple version of the model.

Figure 1: Sequence of events in the simple model

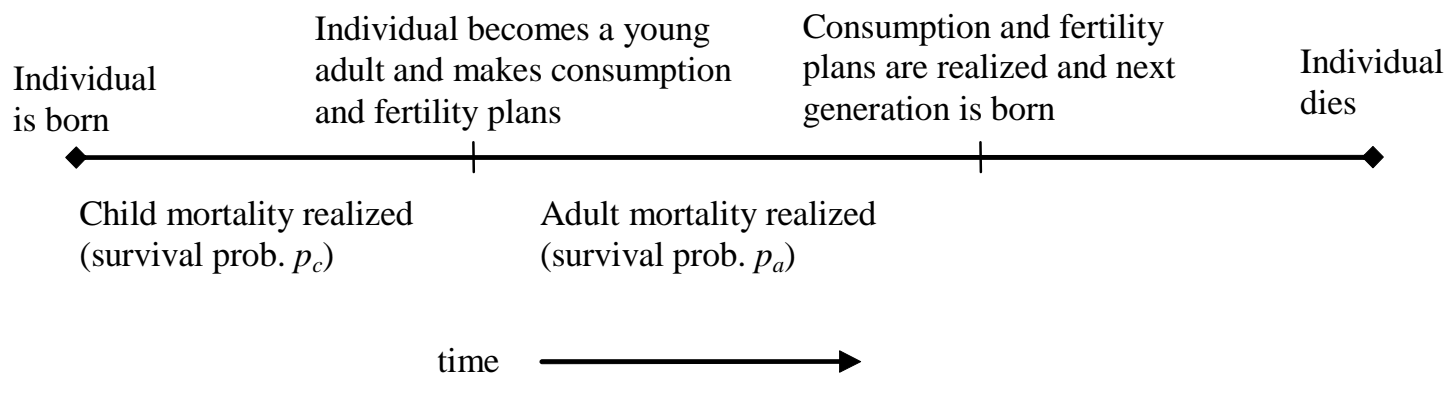

As in Rosen (1988), utility is assumed to be state-dependent in dimensions involving life and death events. We assume that surviving individuals derive utility from consumption and children, but that utility in case of death is equal to a constant $M_{a}$. Similarly, we assume that even though parents derive utility only from surviving children, there is a state-dependent utility loss associated with the death of a child. Therefore, the expected utility for a young adult satisfies the following value function

$$
\widetilde{V}_{t}=\max _{c_{t}, n_{t}}\left\{p_{a}\left\{\widetilde{u}\left(c_{t}\right)+\mathbf{E}\left[\widetilde{v}\left(n_{t}, N_{t}, \widetilde{V}_{t+1}\right)\right]\right\}+\left(1-p_{a}\right) M_{a}\right\}
$$

subject to the constraint (1), where $c_{t}$ is consumption by adults at time $t, n_{t}$ is the number of children born, $N_{t}$ is the number of surviving children, and $\widetilde{V}_{t+1}$ is the future utility that the surviving children will enjoy as they become adults. The function $\widetilde{u}\left(c_{t}\right)$ denotes the utility

\footnotetext{
${ }^{6}$ Note that our assumptions eliminate the traditional quantity-quality trade-off in terms of the analytical results of the model. Parents could still value child quality as human capital if we make the value function depend on human capital. Nevertheless, when the model is applied to data to evaluate different situations, this trade-off will be reflected in different values of the parameters $b$ and $e$, since in equilibrium these reflect the marginal value that parents attach to children.
} 
derived from consumption, and $\widetilde{v}\left(n_{t}, N_{t}, V_{t+1}\right)$ denotes the overall utility derived from children, including the enjoyment from the surviving children and their welfare, and the emotional loss associated with children who are born but do not survive childhood $\left(n_{t}-N_{t}\right)$. Since there is an additional dimension of uncertainty related to the survival of children (probability $p_{c}$ ), parents try to maximize $\widetilde{u}\left(c_{t}\right)$ plus the expected value of $\widetilde{v}\left(n_{t}, N_{t}, V_{t+1}\right)$, conditional on survival into adulthood.

In addition, we assume that the utility derived from surviving children follows the usual formulation from the fertility literature (as, for example, in Becker and Barro, 1988), so that the utility derived from $N_{t}$ surviving children is given by $\alpha N_{t}^{\phi} V_{t+1}$, with $0 \leq \phi \leq 1$. As mentioned before, we also consider a state-dependent utility loss of $\alpha M_{c}$ for each child born who does not survive childhood. The utility loss associated with the death of $\left(n_{t}-N_{t}\right)$ children is given by $\alpha\left(n_{t}-N_{t}\right) M_{c}$. In our setting, $M_{c}$ will have the connotation of the utility value associated with the loss of one child (regardless of family characteristics). This is a state-dependent formulation in the event of death of a child, analogous to the approach adopted by Rosen (1988) in relation to adult deaths. Finally, in order to simplify the analysis, we assume that there is no uncertainty about child quality or, in other words, that the series $\left\{w_{i}\right\}_{i=t}^{\infty}$ is known. Therefore, there is no uncertainty regarding the value of $V_{t+1}$ itself.

In this context, we can normalize adult utility in the death state to zero by defining the instantaneous utility function $u\left(c_{t}\right)=\tilde{u}\left(c_{t}\right)-M_{a}$. By defining the value function $V_{t}=\widetilde{V}_{t}-M_{a}$, we can specify a young adult's objective function as

$$
V_{t}=\max _{c_{t}, n_{t}}\left\{p_{a}\left\{u\left(c_{t}\right)+\alpha \mathbf{E}\left[N_{t}^{\phi} V_{t+1}-\left(n_{t}-N_{t}\right) M_{c}\right]\right\}\right\} .
$$

Note that there are two different dimensions of uncertainty in the problem. One is related to whether the individual will die before being able to realize the consumption and fertility plans, while the other is related to the number of children who survive $\left(N_{t}\right)$ out of the total number of children born $\left(n_{t}\right)$. Since the value function is defined as the expected utility of an adult individual, the only remaining dimension of uncertainty after the individual survives adult mortality is related to the number $N_{t}$ of children who will survive out of $n_{t}$ births.

This problem is as close as possible to the one discussed in Rosen (1988, Section 1), once fertility and altruism are incorporated in the analysis. Nevertheless, altruism and fertility introduce new, nontrivial dimensions of uncertainty in the discussion. Since one of our main motivations is to explore child mortality in a context of value of life calculations, we deal explicitly with the uncertainty related to $p_{c}$. Following Sah (1991), with constant $p_{c}$, the number of surviving children $N_{t}$ follows a binomial distribution with density function 


$$
f\left(N_{t}, n_{t}\right)=\left(\begin{array}{c}
n_{t} \\
N_{t}
\end{array}\right) p_{c}^{N_{t}}\left(1-p_{c}\right)^{n_{t}-N_{t}}, \text { for } N_{t}=0,1,2, \ldots, n_{t} .
$$

Therefore,

$\mathbf{E}\left[N_{t}^{\phi} V_{t+1}-\left(n_{t}-N_{t}\right) M_{c}\right]=\mathbf{E}\left[N_{t}^{\phi} V_{t+1}\right]-\mathbf{E}\left[\left(n_{t}-N_{t}\right) M_{c}\right]=V_{t+1} \sum_{N_{t}=0}^{n_{t}} N_{t}^{\phi} f\left(N_{t}, n_{t}\right)-\left(1-p_{c}\right) n_{t} M_{c}$, since $\mathbf{E}\left(n_{t}-N_{t}\right)=\left(1-p_{c}\right) n_{t}$ and $V_{t+1}$ is known to parents.

As in Kalemli-Ozcan (2002), we approximate the function $\mathbf{E}\left[N_{t}^{\phi}\right]$ around the expected number of survivors $\mathbf{E}\left[N_{t}\right]$ using the delta method. This strategy allows us to deal with fertility as a continuous variable and still account for the effects associated with the risk regarding the number of surviving children via the explicit consideration of the second moment of the distribution. A second order approximation to $\mathbf{E}\left[N_{t}^{\phi}\right]$ leads to

$$
\mathbf{E}\left[N_{t}^{\phi}\right] \approx\left(p_{c} n_{t}\right)^{\phi}-\frac{\phi(1-\phi)\left(1-p_{c}\right)\left(p_{c} n_{t}\right)^{\phi-1}}{2}
$$

since $\mathbf{E}\left[N_{t}-\left(p_{c} n_{t}\right)\right]=0$ and the variance for the binomial distribution satisfies $\mathbf{E}\left[N_{t}-\left(p_{c} n_{t}\right)\right]^{2}=$ $n_{t} p_{c}\left(1-p_{c}\right)$. Using this result, the individual problem becomes

$$
V_{t}=\max _{c_{t}, n_{t}} p_{a}\left\{u\left(c_{t}\right)+\alpha\left[\left(p_{c} n_{t}\right)^{\phi}-\frac{\phi(1-\phi)\left(1-p_{c}\right)\left(p_{c} n_{t}\right)^{\phi-1}}{2}\right] V_{t+1}-\alpha\left(1-p_{c}\right) n_{t} M_{c}\right\},
$$

subject to (1).

The first order conditions determining the optimal consumption and fertility decisions are given by the following expressions

$$
\begin{gathered}
p_{a} u_{c}\left(c_{t}\right)=p_{a} \lambda_{t}, \quad \text { and } \\
p_{a} \alpha\left\{\frac{\partial \mathbf{E}\left[N_{t}^{\phi}\right]}{\partial n_{t}} V_{t+1}-M_{c}\left(1-p_{c}\right)\right\}=p_{a}\left(b+e p_{c}\right) \lambda_{t},
\end{gathered}
$$

where $\lambda_{t}$ is the multiplier on the budget constraint and, from the calculations above,

$$
\frac{\partial \mathbf{E}\left[N_{t}^{\phi}\right]}{\partial n_{t}}=\phi\left(p_{c} n_{t}\right)^{\phi-1} p_{c}+\frac{\phi(1-\phi)^{2}\left(1-p_{c}\right)\left(p_{c} n_{t}\right)^{\phi-2} p_{c}}{2} .
$$




\section{Changes in Adult Survival}

The value of changes in life expectancy can be expressed as the marginal willingness to pay for increases in the probabilities $p_{a}$ and $p_{c}$. For $p_{a}$, we define $M W P^{a}$ as:

$$
M W P_{t}^{a}=\frac{\partial V_{t}}{\partial p_{a}} \frac{1}{\lambda_{t}}
$$

This marginal willingness to pay can be interpreted as the monetary value of the marginal utility from increased survival probability, or, alternatively, as the marginal rate of substitution between survival probability and income. From the envelope theorem, this expression can be written as

$$
M W P_{t}^{a}=\frac{u\left(c_{t}\right)+\alpha \mathbf{E}\left[N_{t}^{\phi}\right] V_{t+1}-\alpha M_{c} n_{t}\left(1-p_{c}\right)}{\lambda_{t}}+\frac{p_{a} \alpha \mathbf{E}\left[N_{t}^{\phi}\right]}{\lambda_{t}} \frac{\partial V_{t+1}}{\partial p_{a}}-c_{t}-b n_{t}-\left[p_{c} n_{t}\right] e .
$$

Using the first order conditions, we obtain

$$
M W P_{t}^{a}=\left(\frac{1}{\varepsilon_{c}}-1\right) c_{t}+\left(b+e p_{c}\right)\left(\frac{1}{\varepsilon_{n}}-1\right) n_{t}+p_{a} \alpha \mathbf{E}\left[N_{t}^{\phi}\right] \frac{\partial V_{t+1}}{\partial p_{a}} \frac{1}{\lambda_{t}},
$$

where $\varepsilon_{c}$ and $\varepsilon_{n}$ denote the elasticities of the consumption and fertility sub-utility functions in relation to their respective arguments

$$
\varepsilon_{c}=\frac{\partial u\left(c_{t}\right)}{\partial c_{t}} \frac{c_{t}}{u\left(c_{t}\right)}, \quad \text { and } \quad \varepsilon_{n}=\frac{\partial \mathbf{E}\left[N_{t}^{\phi} V_{t+1}-\left(n_{t}-N_{t}\right) M_{c}\right]}{\partial n_{t}} \frac{n_{t}}{\mathbf{E}\left[N_{t}^{\phi} V_{t+1}-\left(n_{t}-N_{t}\right) M_{c}\right]}
$$

In a stationary environment, we have that $\lambda_{t}=\lambda_{t+1}=\lambda$ and $\frac{\partial V_{t+1}}{\partial p_{a}}=\frac{\partial V_{t}}{\partial p_{a}}=\frac{\partial V}{\partial p_{a}}$. In this case, we can write

$$
M W P^{a}=\frac{1}{1-p_{a} \alpha \mathbf{E}\left[N^{\phi}\right]}\left[\left(\frac{1}{\varepsilon_{c}}-1\right) c+\left(b+e p_{c}\right)\left(\frac{1}{\varepsilon_{n}}-1\right) n\right] .
$$

Equation (5) can be immediately compared to the results from the original value of life literature. It highlights the insights gained by incorporating fertility and altruism in the analysis. Without fertility decisions and altruism, (5) would be reduced to $\left(\varepsilon_{c}^{-1}-1\right) c$, which is exactly the result presented in Rosen $(1988,287)$. This result summarizes the fact that increases in life expectancy will be more valuable for higher levels of consumption and for a lower elasticity of the sub-utility function $u(c)$. However, because higher survival probabilities increase the cost of the actuarially fair insurance, reductions in mortality lower consumption in case of survival. This is precisely the sense in which Rosen (1994) identifies a trade-off between the quantity and the quality of life. 
The second term inside brackets represents an analogous effect in relation to fertility, coming from the fact that increased survival probability increases the likelihood that individuals will live long enough to realize their fertility plans and derive utility from their children. The term $\left(b+e p_{c}\right)$ converts the value of fertility into monetary (consumption) units, while the rest of the expression is completely analogous to the case of consumption. The new expression states that increases in life expectancy will be more valuable in high fertility societies and for low values of the elasticity of the fertility sub-utility in relation to its argument. Again, this last effect derives from the fact that increases in survival probabilities increase the cost of survivors, therefore reducing fertility in case of survival.

Finally, the term outside brackets adjusts the value of life for the fact that not only will these changes affect the current generation, but they will also benefit all future generations. $M W P_{a}$ accounts for the present discounted value of the welfare gains: $\left[\left(\varepsilon_{c}^{-1}-1\right) c+\left(b+e p_{c}\right)\left(\varepsilon_{n}^{-1}-1\right) n\right]$ per generation, discounted at a rate $p_{a} \alpha \mathbf{E}\left[N^{\phi}\right]{ }^{7} \quad$ In order to write the present value of welfare gains for all future generations in an expression as simple as the one above, we assume a stationary environment.

Our methodology therefore evaluates the welfare gain from certain changes in mortality rates if current conditions were maintained indefinitely into the future. In other words, our framework tells us what the value of certain life expectancy improvements would be in a stationary world where the conditions observed in the data persisted forever. To the extent that economies display long-run growth, it will underestimate the true welfare improvements brought about by reductions in mortality rates. Even with these limitations, our setup extends the analysis in a direction that was entirely ignored by the previous literature.

The results discussed in this section neatly illustrate the features incorporated in the valuation of adult mortality changes once fertility and altruism are taken into account. Apart from the usual effects, a permanent decline in adult mortality benefits current and future generations due to altruistic links, and to the higher probability that adults will live long enough to have children. In reality, the establishment of an altruistic link between parents and children ends up incorporating the welfare gains of all future generations. In our framework, the weight attributed to these future generations is directly related to the value that current adults-the actual decision-makers-attribute to their own children.

In addition to these gains, there are important aspects of changes in child mortality and their

\footnotetext{
${ }^{7}$ For this to be the case, we must have $p_{a} \alpha \mathbf{E}\left[N^{\phi}\right]<1$, which is precisely the condition required for the recursive problem described before to be well defined. Note also that the homogeneity of the value function, characteristic of the deterministic version of Becker and Barro (1988), fails to hold in the presence of child mortality under our state-dependent forumlation. Our assumption of zero income growth allows us to obtain a closed form solution for the problem even in the absence of homogeneity.
} 
interactions with fertility that are distinct in nature from the effects of changes in adult mortality. We now explore these implications within the framework of our model.

\section{Changes in Child Survival}

We define $M W P^{c}$ as the marginal willingness to pay of adults for increases in $p_{c}$. As we stated before, parents, not children, express their concern for survival and their willingness to pay for mortality changes. From the envelope theorem and using the first order conditions, we can write $M W P^{c}$ as

$$
\begin{aligned}
M W P_{t}^{c}=\frac{\partial V_{t}}{\partial p_{c}} \frac{1}{\lambda_{t}}=[(b+ & \left.\left.p_{c} e\right)\right] \frac{p_{a} \phi\left(p_{c} n_{t}\right)^{\phi-1} n_{t}+p_{a} \frac{\phi(1-\phi)^{2}\left(1-p_{c}\right)\left(p_{c} n_{t}\right)^{\phi-2} n_{t}+\phi(1-\phi)\left(p_{c} n_{t}\right)^{\phi-1}}{2}}{\phi\left(p_{c} n_{t}\right)^{\phi-1} p_{c}+\frac{\phi(1-\phi)^{2}\left(1-p_{c}\right)\left(p_{c} n_{t}\right)^{\phi-2} p_{c}}{2}} \\
& +\frac{p_{a} \alpha\left[\left(p_{c} n_{t}\right)^{\phi}-\frac{\phi(1-\phi)\left(1-p_{c}\right)\left(p_{c} n_{t}\right)^{\phi-1}}{2}\right]}{\lambda_{t}} \frac{\partial V_{t+1}}{\partial p_{c}}-p_{a} e n_{t}+\frac{p_{a} \alpha M_{c} n_{t}}{\lambda_{t}}
\end{aligned}
$$

or more compactly as

$$
M W P_{t}^{c}=\frac{p_{a}}{p_{c}}\left\{b n_{t}+\frac{(1-\phi)}{2+(1-\phi)^{2} \mu^{2}}\left(b+p_{c} e\right)\right\}+p_{a} \alpha\left\{\mathbf{E}\left[N_{t}^{\phi}\right] \frac{\partial V_{t+1}}{\partial p_{c}}+M_{c} n_{t}\right\} \frac{1}{\lambda_{t}},
$$

with $\mu=\sqrt{\operatorname{Var}(N)} / \mathbf{E}[N]$ as the coefficient of variation.

Again, in a stationary environment we can write

$$
M W P^{c}=\frac{1}{1-p_{a} \alpha \mathbf{E}\left[N^{\phi}\right]} \frac{p_{a}}{p_{c}}\left[b n+\frac{(1-\phi)}{2+(1-\phi)^{2} \mu^{2}}\left(b+p_{c} e\right)+p_{c} \frac{\alpha M_{c}}{u_{c}(c)} n\right] .
$$

The term transforming the flow of welfare into its present discounted value multiplies the expression as in the marginal willingness to pay for changes in adult survival rates. Changes in child mortality are assumed to be permanent, and, therefore, they will be enjoyed not only by this generation but also by all future generations.

In the case of child mortality, three elements compose the valuation of mortality changes for any given generation (the expression multiplying the discount factor). The first term inside square brackets $(b n)$ represents savings for households due to lower costs in the acquisition of survivors, while the second term derives exclusively from uncertainty considerations. The last term represents the increased welfare from the reduced probability of death of a child $\left(\alpha M_{c}\right.$ per child monetized by $\left.u_{c}(c)\right)$.

Three extreme examples help clarify the economic forces at work here. First, with risk neutrality $(\phi=1)$, the second term inside brackets disappears. In this case, the goods cost per child born and the utility cost per child dead determine the marginal willingness to pay for reductions 
in child mortality. Risk neutrality in this context can also be interpreted as perfect replacement in fertility, since parents have no incentive for fertility insurance or hoarding motives. One can think of it as if children could be replaced immediately after they died, and there was no need to decide on the number of children before child mortality was realized. ${ }^{8}$

Second, consider the other extreme when $0<\phi<1$ and $b=M_{c}=0$. Here, the goods cost of children is defined only for survivors, and there is no welfare loss due to the death of a child. Hence, the value of changes in child mortality depends only on the risk premium due to uncertainty. In this case, even without additional economic costs, reductions in child mortality may improve welfare since increased chances of child survival reduce parents' uncertainty.

Finally, if we have $\phi=1$, still with $M_{c}=b=0$, there are no gains from reductions in child mortality. In this situation, the number of births adjusts on a one-to-one basis to changes in child mortality, and all costs of children are defined in terms of survivors. As parents are risk neutral and there is no cost wedge between children born and surviving children, parents have a target number of expected survivors that is maintained irrespective of the child mortality rate.

In summary, two elements compose the valuation of reductions in child mortality: costs of nonsurviving children (both monetary and utility losses) and reductions in the uncertainty associated with surviving children. These gains are different in nature from the traditional valuations in Arthur (1981) and Rosen (1988), and deserve particular attention in an attempt to attach social values to health improvements. In our setup, the willingness to pay for changes in child mortality is not expressed by the individuals who are subject to the mortality risk, since these individuals (children) are not legal decision-makers and, in some circumstances, have not yet been born. This is precisely why a framework that adequately accounts for the value of changes in child mortality must incorporate fertility as a choice variable, and must express welfare through the perspective of parents and their altruism toward children.

\section{General Model}

This section generalizes the model presented before. Our goal is to obtain expressions that allow the valuation of specific mortality changes for an adult individual at any given age. With that in hand, the model can be used to determine the social value of any change in survival probabilities.

As will be clear below, a critical variable for the calculation of the social value of mortality changes is the value of these changes for an individual entering adulthood. Therefore, we start by

\footnotetext{
8 Estimates of the extent of behavioral replacement effects are often below one with point estimates near or below one-half. That is, additional births do not completely replace child deaths in the family. See Wolpin (1997, Section 2.5) for a survey of empirical results.
} 
considering the expected discounted utility for a representative individual entering adulthood at age $a$ :

$$
V_{T}^{a}=\int_{a}^{\infty} u(c(t)) S(t, a) d t+\alpha S(\tau, a)\left\{\mathbf{E}\left[N_{T}^{\phi}\right] V_{T+1}^{a}-\left(1-p_{c}\right) n_{T} M_{c}\right\}
$$

where $S(t, a)$ is the discounted survivor function, or the function describing the probability that the agent survives from ages $a$ to $t$, discounted at the rate of time preference. ${ }^{9}$ At age $a$, individuals decide their profile of consumption throughout life, and at age $\tau>a$, parents realize their fertility plans. All children are assumed to be born at the same time $\tau$. $V_{T+1}^{a}$ reflects the children's utility once they reach adulthood at age $a$. Since the value function refers to different generations, $T$ indexes generations and $t$ indexes ages. $N_{T}$ represents the number of children surviving to age $a$ out of a total number of births $n_{T}$, from parents belonging to generation $T$. The difference between survivors and births corresponds to the effects of mortality on children.

For the sake of simplicity, we abstract from the dynamic nature of the child-rearing process. In line with the formulation of the previous section, we assume that children are born, face all the risks related to child and pre-adult mortality at one single moment, and immediately become adults. In terms of the undiscounted survival function $S^{*}(t, i)$, we only consider the final survival probability between ages 0 and $a, p_{c}=S^{*}(a, 0)$, where, as before, $p_{c}$ represents the total survival probability for children. We revisit this issue when calibrating the model (see Section 4).

As in the previous section, we consider explicitly the role of uncertainty and assume that the number of surviving children behaves as a random variable with binomial distribution (see equation (3)). The rest of the model remains unchanged: parents have access to an actuarially fair insurance for every good they consume, and they pay a fixed cost per child born and an additional cost per child reaching adulthood. Therefore, for a given endowment $W_{T}$ received by a member of generation $T$ at age $a$, households have the following budget constraint

$$
W_{T}=\int_{a}^{\infty} c(t) S(t, a) d t+S(\tau, a)\left(b n_{T}+e\left[p_{c} n_{T}\right]\right)
$$

where the interest rate is assumed to be equal to the subjective discount rate.

This formulation keeps the basic features discussed before, but adds a couple of new dimensions in terms of the impact of adult mortality reductions across different age groups. For example, adult mortality reductions taking place before fertility decisions are realized $(\tau)$ have now qualitatively different impacts from mortality reductions taking place after that. Or, alternatively,

\footnotetext{
${ }^{9}$ If $S^{*}(t, a)$ is the survival function, the discounted survival function is given by $S(t, a)=e^{-\rho(t-a)} S^{*}(t, a)$, where $\rho$ is the subjective discount rate. Strictly, consumption should also be indexed by generation, as in $c_{T}(t)$, indicating the consumption of generation $T$ at age $t$. We use the discounted survival function and write $c(t)$ to save on notation.
} 
adult mortality changes related to ages below that of parents, which therefore do not affect their personal survival, may still affect their welfare through intergenerational links.

First order conditions in this case are almost identical to those discussed in the simpler version of the model. To evaluate changes in mortality in this context, we think of shifts in the survival function as caused by changes in some underlying parameter $\theta$. In this sense, we define $S_{\theta}(t, i)=$ $\partial S(t, i ; \theta) / \partial \theta$ as the change in the conditional discounted probability of survival from age $i$ to age $t$ brought about by a change in $\theta$.

\subsection{The Problem of an Individual Entering Adulthood}

\section{Changes in Adult Survival}

We start with the problem of an individual entering adulthood, at age $a$. As we mentioned before, this individual will be key in allowing for the valuation of mortality changes for individuals in any age group. We label the willingness to pay of generation $T$ at age $a$ for changes in adult survival as $M W P_{a}^{A}$. As before, we express the value of changes in life expectancy as the marginal willingness to pay for increases in survival probabilities $\left(S_{\theta}(t, a)\right)$ :

$$
M W P_{a}^{A}=\frac{\partial V_{T}}{\partial \theta} \frac{1}{\lambda_{T}^{a}} .
$$

Using the envelope theorem and the first order conditions the same way as we did before, we arrive at a similar expression for $M W P_{a}^{A}$. In a stationary environment, we have $\partial V_{T} / \partial \theta=$ $\partial V_{T+1} / \partial \theta$ and $\lambda_{T+1}=\lambda_{T}$, so that

$$
M W P_{a}^{A}=\frac{1}{1-\alpha S(\tau, a) \mathbf{E}\left[N^{\phi}\right]}\left[\int_{a}^{\infty}\left(\frac{1}{\varepsilon_{c}}-1\right) c(t) S_{\theta}(t, a) d t+S_{\theta}(\tau, a)\left(b+p_{c} e\right)\left(\frac{1}{\varepsilon_{n}}-1\right) n\right] .
$$

When mortality reductions affect survival probabilities before age $\tau$, individuals also benefit directly from the increased probability of living long enough to have children. Since individuals are altruistic, they are willing to pay to ensure new generations through the realization of fertility decisions. This same force is not present when changes in mortality only affect survival rates after age $\tau$.

\section{Changes in Child Survival}

The case of changes in child survival is completely analogous to the simpler version of the model. We define $M W P_{a}^{C}$ as the marginal willingness to pay of an adult at age $a$ for increases in $p_{c}$. Using 
the envelope theorem and the first order conditions, and looking at a stationary environment, we obtain an expression almost identical to equation (6):

$$
M W P_{a}^{C}=\frac{1}{1-\alpha S(\tau, a) \mathbf{E}\left[N^{\phi}\right]} \frac{S(\tau, a)}{p_{c}}\left[b n+\frac{(1-\phi)}{2+(1-\phi)^{2} \mu^{2}}\left(b+p_{c} e\right)+\frac{\alpha p_{c} M_{c}}{u_{c}(c)} n\right] \frac{\partial p_{c}}{\partial \theta} .
$$

The interpretation of the different terms in the equation above was already discussed in Section 2.

\subsection{The Problem of a Young Adult}

To apply the model to heterogeneous populations, we have to extend it to deal with the problem of adult individuals at different ages. We define young adults as individuals who have not yet acted on their fertility choices. For these individuals at age $i$, where $a \leqslant i<\tau$, the questions involved are similar to the ones discussed in Section 3.1, but for one small detail. Since individuals will not necessarily be at age $a$, we will not be able to isolate $\partial V_{T}^{a} / \partial \theta$ on the left hand-side in order to obtain a simple expression for the marginal willingness to pay, as we did before. This is exactly why $M W P_{a}^{C}$ and $M W P_{a}^{A}$ play such critical roles. We can use the results from Section 3.1 to overcome this problem and value changes in mortality at any age between $a$ and $\tau$.

\section{Changes in Adult Survival}

We define the marginal willingness to pay of an individual at age $i$ for changes in adult survival rates, brought about by a change in $\theta$, as $M W P_{i}^{A}=\frac{1}{\lambda_{T}^{i}} \frac{\partial V_{T}^{i}}{\partial \theta}$. Following the same steps as before,

$$
M W P_{i}^{A}=\int_{i}^{\infty}\left(\frac{1}{\varepsilon_{c}}-1\right) c(t) S_{\theta}(t, i) d t+S_{\theta}(\tau, i)\left(b+p_{c} e\right)\left(\frac{1}{\varepsilon_{n}}-1\right) n_{T}+\frac{\alpha S(\tau, i) \mathbf{E}\left[N_{T}^{\phi}\right]}{\lambda_{T}^{i}} \frac{\partial V_{T}^{a}}{\partial \theta} .
$$

But note that the marginal willingness to pay refers to an individual at age $i$, while the derivative of the value function in the right-hand side refers to an individual at age $a$. Therefore, we cannot transfer the derivative of the value function to the left hand-side in order to obtain the present discounted value of changes in mortality for all future generations. However, given our results from the previous section, this is not necessary. Since the solution to the individual problem of a young adult is time consistent, the multiplier on the budget constraint will always have the same value in a stationary environment, irrespective of generation or age (this can be seen from the first order conditions and the budget constraint). In a stationary environment, this means that the marginal utility of wealth (or the multiplier) will be constant within and across generations, so that we can write: $\lambda_{T+1}^{i}=\lambda_{T+1}^{a}=\lambda_{T}^{a}=\lambda_{T}^{i}$ and 


$$
\frac{1}{\lambda_{T+1}^{i}} \frac{\partial V_{T+1}^{i}}{\partial \theta}=\frac{1}{\lambda_{T+1}^{a}} \frac{\partial V_{T+1}^{a}}{\partial \theta}=\frac{1}{\lambda_{T}^{a}} \frac{\partial V_{T}^{a}}{\partial \theta}=M W P_{a}^{A} .
$$

This result yields

$$
M W P_{i}^{A}=\int_{i}^{\infty}\left(\frac{1}{\varepsilon_{c}}-1\right) c(t) S_{\theta}(t, i) d t+S_{\theta}(\tau, i)\left(b+p_{c} e\right)\left(\frac{1}{\varepsilon_{n}}-1\right) n_{T}+\alpha S(\tau, i) \mathbf{E}\left[N_{T}^{\phi}\right] M W P_{a}^{A}
$$

As this expression makes clear, $M W P_{a}^{A}$, or the marginal willingness to pay of an individual at age $a$, is a key concept in the problem. Our willingness to pay measure allows the valuation of future generations to be incorporated via the altruism of parents. In this case, the willingness to pay of parents at age $i$ is composed, as before, by the consumption and fertility factors, plus the discounted value of these gains for their children. In turn, children will become adults when their parents are $\tau$ years old. The meaning of this expression is exactly the same as equation (9), the only difference being that parents' marginal willingness to pay will not be exactly the same as their children's. Therefore, it is not possible to express $M W P_{i}^{A}$ directly as the simple discounted value of the sum of the consumption and fertility factors.

\section{Changes in Child Survival}

For changes in $\theta$ that affect child mortality, the result is also analogous to the expression for a young adult at age $a$. We define the marginal willingness to pay of an individual at age $i$ for improvements in child survival as $M W P_{i}^{C}=\frac{\partial V_{T}^{i}}{\partial \theta} \frac{1}{\lambda_{T}^{i}}$, such that

$$
M W P_{i}^{C}=\frac{S(\tau, i)}{p_{c}}\left[\left(b+\frac{\alpha p_{c} M_{c}}{u_{c}(c(t))}\right) n_{T}+\frac{(1-\phi)}{2+(1-\phi)^{2} \mu^{2}}\left(b+p_{c} e\right)\right] \frac{\partial p_{c}}{\partial \theta}+\alpha S(\tau, i) \frac{\mathbf{E}\left[N_{T}^{\phi}\right]}{\lambda_{T}^{i}} \frac{\partial V_{T+\tau}^{a}}{\partial \theta}
$$

As before, in a stationary environment, time consistency of the individual's problem allows us to write

$M W P_{i}^{C}=\frac{S(\tau, i)}{p_{c}}\left\{\left(b+\frac{\alpha p_{c} M_{c}}{u_{c}(c(t))}\right) n_{T}+\frac{(1-\phi)}{2+(1-\phi)^{2} \mu^{2}}\left(b+p_{c} e\right)\right\} \frac{\partial p_{c}}{\partial \theta}+\alpha S(\tau, i) \mathbf{E}\left[N^{\phi}\right] M W P_{a}^{C}$.

This expression has the same interpretation as equation (10). The only difference is that altruism for future generations is expressed via the discounted value of the marginal willingness to pay of individuals entering adulthood $\left(M W P_{a}^{C}\right)$, and not of individuals at the same age as their parents. 


\subsection{The Problem of an Old Adult}

For those individuals at age $i>\tau$, fertility decisions have already been realized. As mentioned before, we assume that these individuals cease to be altruistic toward their offspring. A normative interpretation of this hypothesis, mentioned in the introduction, is that the inclusion of forms of altruism not related to the parent-children relationship is less justifiable, and not nearly as important, as the inclusion of the altruism of parents toward young children. The altruism of older parents toward their 40-year-old sons and daughters does not seem too different from the altruism of friends toward each other. Few would argue that the latter should be taken too seriously or, in any case, that it would have any major effect in welfare analysis (but see the important discussion in Bergstrom, 2006).

With the hypothesis of egoistic old adults, the problem of an individual at age $i>\tau$ turns into the classical problem of the value of life literature, without altruism and without fertility. If mortality reductions take place in age groups that do not directly benefit the individual, the marginal willingness to pay is zero. If mortality reductions take place at some age after $i$, we are back to the traditional value of life setup. We define the marginal willingness to pay of an old adult for changes in $\theta$ as $M W P_{i}^{O}$, and write:

$$
M W P_{i}^{O}=\int_{i}^{\infty}\left(\frac{1}{\varepsilon_{c}}-1\right) c(t) S_{\theta}(t, a) d t .
$$

This corresponds to what we called before the consumption factor. It represents the goods trade-off between quantity and quality of life identified by Rosen (1994)..$^{10}$

\subsection{Social Value of Mortality Reductions}

With the previous results in hand, we are able to determine the social value of any given change in the survival function. The social value will be a function of the age distribution of the population, and of the valuation attached to the changes by each specific age group. The valuation of each age group will ultimately depend on the moment and extent of the observed reductions in mortality.

Suppose that a population of $P$ individuals is distributed across ages according to the distribution function $F(\cdot)$. The social value of a given change in mortality rates, brought about by a shift in the parameter $\theta$, is given by

\footnotetext{
10 Though certainly extreme and concentrated at one point in time, the distinction between young and old adults captures the idea that the value that parents place on a child's life is reduced as the child ages. This pattern has been noticed in the empirical literature (Jenkins, Owens, and Wiggins, 2001).
} 


$$
\text { Social } M W P=P\left[\int_{a}^{\tau}\left(M W P_{i}^{C}+M W P_{i}^{A}\right) d F(i)+\int_{\tau}^{\infty} M W P_{i}^{O} d F(i)\right] .
$$

Or, defining

$$
M W P_{i}=\left\{\begin{array}{c}
M W P_{i}^{C}+M W P_{i}^{A}, \text { if } i \leqslant \tau \text { and } \\
M W P_{i}^{O}, \text { if } i>\tau
\end{array}\right.
$$

we can write it in a simpler form

$$
\text { Social } M W P=P \int_{a}^{\infty} M W P_{i} d F(i) .
$$

The social value is simply the weighted sum of the value of mortality changes across the different age groups, where the weights are given by the number of individuals in the population that belong to each specific group $(P d F(i))$. It is immediate to see that the age distribution may have a significant impact on the social value of a specific change in survival probabilities. A society with a high proportion of old individuals will value reductions in child or young adult mortalities less, and value extensions in old age life expectancy more.

Also notice that our aggregate willingness to pay only incorporates individuals at age $a$ or older. From a policy perspective, these are the actual decision-makers and the individuals who incur the costs of child raising. Legally, they are the ones who are allowed to decide and who can interfere directly in the political process. Children and future generations only enter the social willingness to pay via the altruism of current adults. This structure captures in a stylized way the actual process of political decision observed in modern societies.

In reality, equation (13) is analogous to the characterization of the optimal provision of a public good common in the public finance literature. Equation (13) gives the maximum amount of taxes that should be raised on the current population in order to promote a given reduction in mortality rates (a change in $\theta$ ). The key difference here is that our measure of social willingness to pay incorporates the gains of children and future generations. These are considered to the extent that current adults-due to the links established by intergenerational altruism-are willing to pay for the welfare gains of their descendents. Indeed, equation (13) characterizes the optimal allocation from the perspective of the costs and benefits faced by the population currently alive. ${ }^{11}$

\footnotetext{
11 This is very different from the approach taken by Murphy and Topel (2003) or Soares (2006). Murphy and Topel (2003) and Soares (2006) incorporate future generations by simply extrapolating current numbers and discounting future populations at the interest rate. This amounts to assuming a specific type of intergenerational welfare function that, as every other welfare function, is arbitrary. For example, given the preferences they assume, their numbers would not be supported by voters as policy benchmarks for the benefits of improvements in health.
} 


\section{Parametrization and Empirical Implications}

\subsection{Calibration}

In order to illustrate the importance of the dimensions added by our framework, we use the model developed in the previous section to give monetary values to the mortality reductions experienced by the United States population between 1965 and 1995. Though part of the improvements in health during this period were endogenous to changes in habits and income, our goal is simply to use this example to show how important fertility and altruism can be in assessing the economic value of reductions in mortality. This is a case that has been studied in the literature and, therefore, constitutes a good initial example. In addition, the United States is one of few countries for which alternative estimates of the "values of a statistical life" for both adults and children are currently available. $^{12}$

We look at the problem from the perspective of individuals alive in 1965, and ask how much they would be willing to pay for the gains in survival probabilities that actually took place in the following 30 years. As discussed previously, the numbers generated by the methodology assume that individuals consider the economic conditions prevalent in 1965 as the ones that would persist indefinitely into the future. As the marginal willingness to pay increases with income, the perspective of economic growth would increase the value of mortality reductions and even more so for future generations. So, as with many other dimensions of our empirical strategy, this assumption tends to reduce both the value of life expectancy gains and the relative importance of altruism and fertility. As a general rule, whenever faced with choices regarding the implementation of our methodology, we choose to proceed with the option that minimizes the importance of the very factors we want to highlight. In this manner, we hope to guarantee that any remaining bias will work against the relevance of our main points. To proceed, we need values for a series of parameters and variables determining initial conditions $\left(c, n_{T}, b, e, \phi, \alpha\right.$, and the interest rate), the survival function $\left(S^{*}(t, a)\right)$, and the change in the survival function between 1965 and 1995 $\left(S_{\theta}^{*}(t, a)\right)$.

The U.S. survival functions for 1965 and 1995 are calculated from age-specific number of deaths and population, obtained from the World Health Organization Mortality Database. The WHO database contains information broken down by 5 -year age intervals, so we assume constant mortality rates within each interval. We calculate the 1965 numbers as averages for the period between 1960 and 1969, and the 1995 numbers as averages between 1990 and 1999. Figure 1

\footnotetext{
12 The changes observed during the period are quite substantial. But, given the complexity of the problem at hand, closed form solutions cannot be obtained for the valuation of discrete changes in survival probabilities. Therefore, we stick to the formulas derived before for the marginal willingness to pay, and see our results as approximations of the true welfare value of mortality reductions.
} 
illustrates the shift in the (undiscounted) survival function for the U.S. population between 1965 and 1995. This shift corresponds to a change in overall life expectancy at birth from 70 to 76 years. Note that the U.S. experienced relatively modest gains in child mortality during this period, mainly because of the already extremely low starting point (mortality before age 5 went from $2.84 \%$ to 0.99\%). Also, the age distribution of the American population in 1965 had a relatively high share of old adults when compared to young adults (36\% of the population above age 40 ). If anything, the example chosen tends to minimize the importance of altruism, fertility, and future generations in the calculation of the social value of mortality reductions.

Figure 2: Survival Probabilities for the U.S. Population (from age 0 to $t$ ), 1965 and 1995

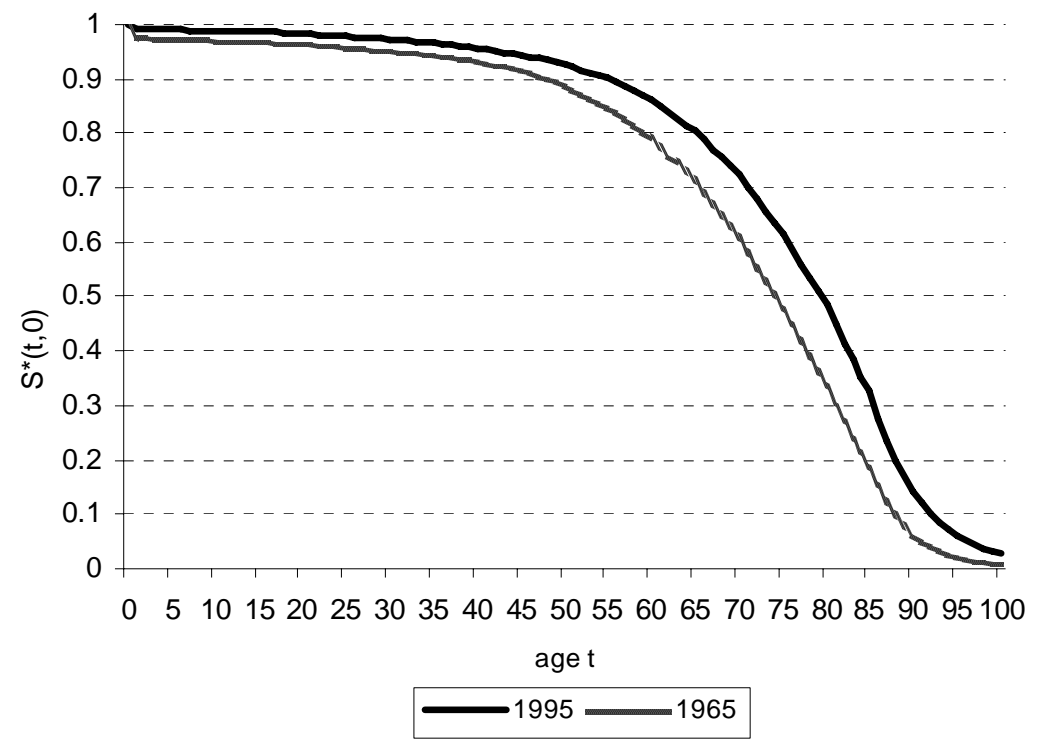

Of the parameters and variables needed, some are common in the "value of life" literature. First, interest rates are assumed to be $3 \%$ per year, and this number is used to calculate the discounted survival functions $(S(t, a))$. The assumption of subjective rate of time preference equal to the interest rate implies constant consumption throughout life. Since we are not interested in life-cycle considerations, and this facilitates the empirical implementation of the model, it is the best way to proceed. This allows the consumption term in the willingness to pay expressions to be factored as $\left(\varepsilon_{c}^{-1}-1\right) c \int_{i}^{\infty} S_{\theta}(t, i) d t$. Consumption is set to the 1965 value of total per capita consumption $(\$ 13,835$, equal to private plus government consumption in 1996 US\$), obtained from the Federal Reserve Board Economic Database (FED). ${ }^{13}$ Following Becker, Philipson, and

\footnotetext{
13 Murphy and Topel (2003) incorporate leisure in the analysis and obtain a measure of full-income. Therefore,
} 
Soares (2005), we assume that the instantaneous utility function for consumption takes the form $u(c)=\varphi+c^{\sigma} / \sigma$, which already incorporates the normalization of utility of death to zero (as in the formulation proposed by Rosen, 1988). We also stick to the calibration proposed by these authors, where $\varphi=-16.16$ and $\sigma=0.2$.

For fertility $\left(n_{T}\right)$, the survival probability of children $\left(p_{c}\right)$, and the discounted survival probability of adults up to the age when fertility is realized $(S(\tau, a))$, we use the 1965 values of, respectively, the total fertility rate $\left(2.9\right.$, or $n_{T}=1.45$, from the World Development Indicators, WDI), the survival probability between ages zero and 18 (0.96), and the discounted survival probability between ages 18 and $40(0.50)$. We take $p_{c}$ to be the survival probability from zero to eighteen because 18 years of age seem to be the natural benchmark for legal independence of children. Besides, this timing matches well the data on the costs of raising children, which will be used to calibrate some of the remaining parameters. In relation to the age when fertility is realized, we choose $\tau=40$. Since we are consolidating the entire child-rearing process in a single moment, we choose the middle point of the parenthood process as such moment. If one thinks that parents usually start having children when they are between 25 and 30 , and take care of children in one way or another until they are roughly 50 or 55 , the middle point would be around age 40 .

Estimates of the costs of raising a child ( $b$ and $e$ ) can be obtained from surveys of expenditures on children, such as the ones undertaken by the U.S. Department of Agriculture (USDA). Lino (2001) presents the 1960 estimates of the USDA for the average costs of raising a child up to age 18, in 2000 US\$. We use the CPI to deflate this value to 1996 US\$. The USDA estimates imply that roughly $5 \%$ of the expenditures on children takes place before age 2 , while $95 \%$ takes place between ages 2 and 18. We assume that costs up to age 2 are related to the costs of having a child (b), and costs between ages 2 and 18 are related to costs of raising a surviving child $(e)$. This yields $b=\$ 6,956$ and $e=\$ 126,812$. Again, if anything, these estimates seem to underestimate the value of $b$ in comparison to $e$, and this will tend to minimize the importance of child mortality in welfare evaluations.

The remaining parameters needed $-\alpha, \phi$, and $M_{c}$-are uncommon in applied work and, as far as we understand, have never been directly estimated in the literature. Therefore, some exploratory calibration effort is required, involving a subtler type of information that is not so widely available. Calibration of these parameters requires knowledge of how much individuals value their own survival probabilities vis-à-vis their children's. There is a small empirical literature, based on

their numbers are larger than the ones obtained here. Murphy and Topel (2003) also deal explicitly with the issue of life-cycle changes in earnings and consumption. To keep things simple and to focus on the points of interest, we abstract from these considerations. 
interpersonal willingness to pay for changes in mortality, that addresses this type of question.

Cropper, Aydede, and Portney (1992), for example, use a survey to estimate the rate at which people implicitly discount future lives saved. But their questions do not imply any kind of personal relationship among the individuals being considered and, therefore, are not adequate for our analysis. Carlin and Sandy (1991) use car safety seat information to estimate the "value of a statistical life" of children to their mothers, but do not present comparable numbers for adults. Dickie and Ulery (2001) use a contingent valuation survey to estimate parents' willingness to pay for various health conditions affecting themselves and their children. These authors find that parents are willing to pay more for their children's health than for their own (willingness to pay to avoid acute illnesses), but do not address directly the issue of mortality.

Three papers use information on adult decisions to estimate the "values of a statistical life" for both adults and children, and therefore contain the ideal type of information needed to calibrate our parameters of interest. Blomquist, Miller, and Levy (1996) use a set of different types of data (seat-belt use, child safety-seat use, and motorcycle helmet use) and obtain a wide range of estimates for adults and children. Their preferred estimate for the "value of a statistical life" for adults is $\$ 2$ million, while the average estimate for children is around $\$ 4$ million.

Mount et al. (2000) calculate "values of a statistical life" based on cars owned by different types of families (single or with children) and the safety features of the cars. From the specifications presented by the authors, our preferred value is the one that controls for differences in family income, leading to "values of a statistical life" of $\$ 2.62$ million for children and $\$ 3.88$ million for adults.

Finally, Jenkins, Owens, and Wiggins (2001) make use of data from purchases of bicycle helmets, which are available specifically for people at different age ranges and protect one particular individual within the family. From the estimates presented by the authors, our preferred value is the one that assumes that helmets are worn less than $100 \%$ of the time and that only half of the benefit comes from mortality reductions (the rest being attributed to morbidity). This specification leads to "values of a statistical life" of $\$ 1.3$ million for children and $\$ 2$ million for adults.

Blomquist, Miller, and Levy (1996), Mount et al. (2000), and Jenkins, Owens, and Wiggins (2001) estimate the "values of a statistical life" for children and adults separately, based on costs and safety features associated with the use of seat belts, child safety seats, automobiles, and helmets. These reflect values implicit in decisions taken by adults, matching well our theoretical formalization.

From the theoretical perspective, the "value of a statistical life" can be conceptualized as the 
marginal willingness to pay for a one-shot unit change in the probability of death at some specific age (as in Murphy and Topel, 2003). Therefore, from equations 9 and 10, a given set of estimates of the "values of a statistical life" for adults and children defines-together with the variables discussed before-two non-linear equations on three unknown parameters $\left(\alpha, \phi\right.$, and $\left.M_{c}\right)$. The first order conditions for $c_{t}$ and $n_{T}$ can be used to define a third equation, which, together with the previous two, defines a system of three equations on three unknowns.

Table 1: Benchmark Variables for Base Year (1965) and for Calibration (1995)

\begin{tabular}{c|c|c|c|c}
\hline \hline Variable & Definition & Source & 1965 & 1995 \\
\hline$p_{c}$ & Survival probability to age 18 & WHO & 0.96 & 0.98 \\
$S(\tau, a)$ & Discounted survival prob. from age 18 to 40 & WHO & 0.50 & 0.51 \\
$c$ & Consumption per capita & FED & 13,835 & 24,640 \\
$n_{T}$ & Fertility rate per parent & WDI & 1.47 & 1.02 \\
$b$ & Child cost before age 2 & USDA & 6,956 & 7,847 \\
$e$ & Child cost from age 2 to 18 & USDA & 126,812 & 143,052 \\
\hline \hline
\end{tabular}

Note: Values of $c, b$, and $e$ in $1996 \$$. Sources and construction of variables described in detail in the text. Values in 1995 used to calibrate $\alpha, \phi$, and $M_{c}$; values in 1965 used as benchmark to calculate the monetary value of the reductions in mortality observed between 1965 and 1995.

Table 2: Estimates of $\alpha, \phi$ and $M_{c}$ Based on the "Value of a Statistical Life" (VSL) for Adults and Children

\begin{tabular}{c|cc|ccc}
\hline \multicolumn{2}{|c|}{ and Children } \\
& \multicolumn{2}{|c|}{ VSL (Mill., 1996 \$): } & \multicolumn{3}{|c}{ Calibrated Values } \\
& Children & Adults & $\alpha$ & $\phi$ & $M_{c}$ \\
\hline Blomquist et al. (1996) & 4.00 & 2.00 & 0.0612 & 0.5753 & 19,563 \\
Mount et al. (2000) & 2.62 & 3.88 & 0.0461 & 0.4755 & 16,858 \\
Jenkins et al. (2001) & 1.30 & 2.00 & 0.0339 & 0.3870 & 11,094 \\
\hline \hline
\end{tabular}

Note: Calibrated values from authors' calculations using the "values of a statistical life" estimated by

Blomquist et al. (1996), Mount et al. (2000), and Jenkins et al. (2001). Calculations based on the three equations described in the Appendix and the values of variables in 1995 presented in Table 1.

Since the studies discussed use data from the 1990's, we set the other variables to their 1995 values in order to solve the system of non-linear equations for $\alpha, \phi$, and $M_{c}$. The Appendix presents the system of three non-linear equations and discusses in detail how this calibration was conducted. For each set of estimates of the "values of a statistical life" for adults and children, we obtain a set of estimates of $\alpha, \phi$, and $M_{c}$. Table 1 presents the values of the variables used 
in the calibration of the parameters and in the calculation of the monetary value of the mortality reductions observed between 1965 and 1995. The calibrated values of $\alpha, \phi$, and $M_{c}$ are shown in Table 2.

In order to give a concrete meaning to the set of parameters presented in Table 2, we can multiply $\alpha$ by $M_{c}$ and divide this product by the marginal utility of consumption in order to get, roughly speaking, the monetary value of the emotional loss associated with the death of a child. The set of parameters calibrated imply that this value is between $\$ 1.2$ million and $\$ 3.9$ million. This is at least one order of magnitude greater than the utility that parents derive from actually having a child, which, from the first order conditions, must be closely related to its marginal cost (the utility from having a child can be expressed, in monetary terms, as $\alpha V_{t+1} / u_{c}(c)$, which revolves around $\$ 100,000$ in the specifications). According to any of the calibrated versions of the model, the utility loss associated with the death of an existing child is orders of magnitude greater than the utility gain from having an additional child.

\subsection{Results}

Table 3 presents the results. It contains the monetary value of child and adult mortality reductions for an individual entering adulthood (age 18) and for the entire American population, according to the different sets of parameters. The table shows that any set of parameters yields a significant effect of changes in child mortality on the welfare of a young adult. The results imply that an 18-year-old individual in 1965 would be willing to pay between $\$ 12,701$ and $\$ 39,780$ for the changes in child mortality observed in the following 30 years, and between $\$ 16,167$ and $\$ 20,191$ for the changes in adult mortality observed in the same period. Reflecting the differences in the "values of a statistical life" used in the calibration, the different sets of parameters lead to differences in the relative importance of reductions in child and adult mortalities. But, in any case, all sets of estimates lead to welfare gains from reductions in child mortality that are of the same order of magnitude as those from reductions in adult mortality. With the Jenkins, Owens, and Wiggins (2001) numbers, the total welfare gain is $79 \%$ higher than what would be estimated by looking at reductions in adult mortality alone, while this difference jumps to $128 \%$ in the calibration based on Mount et al. (2000), and 200\% in the calibration based on Blomquist, Miller, and Levy (1996). These are benefits from child mortality reductions that are enjoyed by young adults and that could not be estimated had we not incorporated altruism and fertility in the analysis.

When we move to the analysis of the social value of mortality changes, the relative importance of child mortality is somewhat reduced, since a large fraction of the 1965 population was composed of old adults who had already surpassed the assumed child-rearing age $(\tau=40)$. Still, Table 3 
shows that the social value estimated by our methodology is between $27 \%$ and $80 \%$ higher than what would be obtained if we looked at adult mortality alone. In terms of values, the results imply that the gains in life expectancy experienced in this 30-year period had a social value between $\$ 5$ trillion and $\$ 7$ trillion. These values correspond to at least 1.7 times the U.S. aggregate GDP in 1965. From this, between $\$ 1$ trillion and $\$ 3$ trillion come directly from the effects of reductions in child mortality, through altruism and fertility, on the welfare of adults.

Table 3: Value of Mortality Reductions in the U.S. Between 1965 and 1995, Different Sets of

\begin{tabular}{c|cccc}
\hline \multicolumn{5}{c}{ Parameters } \\
\hline \hline Parameterization & $M W P_{18}^{C}$ & $M W P_{18}^{A}$ & Social $M W P^{C}$ & $\begin{array}{c}\text { Social } M W P^{A} \\
(\text { Bill., } 1996 \$)\end{array}$ \\
\hline Blomquist et al. (1996) & 39,780 & 20,024 & 3,194 & 3,988 \\
Mount et al. (2000) & 25,787 & 20,191 & 2,071 & 3,986 \\
Note: & 12,701 & 16,167 & 1,020 & 3,798 \\
\hline Authors' calculations based on parameter values presented in Table 2, benchmark variables from
\end{tabular}

Surprisingly, the different sets of parameters lead to reasonably similar magnitudes of the marginal willingness to pay of individuals and of society as a whole. The fact that the different calibrations of $\alpha, \phi$, and $M_{c}$ are based on evidence from very different settings suggests that our strategy is effective in identifying the relevant underlying parameters.

Finally, though the results are quantitatively large and point to the relevance of altruism and fertility in value of life-type calculations, we must repeat that several dimensions of our empirical implementation tend to underestimate the very factors that we are trying to highlight. Indeed, we see the evidence as an extremely strong case in favor of the incorporation of fertility and altruism into the analysis. The assumption that individuals above 40 years have no altruistic concerns toward future generations, the specific example picked (U.S.), and the assumption of no economic growth tend to reduce the relative importance of fertility and altruism. Still, with sets of parameters obtained from very different contexts, we arrive at similar conclusions regarding the relevance of these dimensions when evaluating the welfare impact of mortality reductions.

\section{Concluding Remarks}

This paper develops and applies an extended version of the "value of life" methodology that incorporates altruism and fertility decisions. In doing so, we are able to account for the value 
that parents attribute to reductions in child mortality and to incorporate the welfare of future generations in the evaluation of current health policies. We show that, under these circumstances, the value of adult mortality changes can be decomposed into three factors: the consumption factor from the traditional value of life specification; a fertility factor, which accounts for the welfare improvements related to the higher probability of having children; and an altruism factor, which accounts for the fact that mortality reductions will also be enjoyed by all future generations. The value of changes in child mortality, on its turn, depends on the effect of child mortality reductions on the final costs of child production, on the uncertainty regarding the number of surviving children, and on the emotional loss associated with the death of a child. As with adult mortality, child mortality reductions are also valuable because they are experienced by all future generations.

Applying our framework to value the changes in mortality observed in the U.S. between 1965 and 1995, we show that altruism and fertility can double the estimated welfare gain of a young adult. In relation to the aggregate social value, the increase is between $27 \%$ and $80 \%$.

The paper also has implications for the evaluation of any other dimension of public policy that may have long-lasting effects (environmental policy, infrastructure development, technological improvements, etc.). The same principle used here to evaluate the welfare gain of future generations can also be applied in these other contexts. Altruism is a natural link between generations that immediately brings together the welfare gains of all future cohorts. And, from the perspective of the population currently alive, these gains are incorporated in a way that reflects precisely the value that public policy should attribute to future populations.

Finally, our modelling of the way parents value the utility of children and their survival delivers a series of results remarkably consistent with casual observations. For example, when deciding over the custody of a baby, King Solomon-in the biblical example (1 Kings 3:16-28)-threatens to split the live baby in half. When one woman accepts the compromise, but the other claims that the baby does not belong to her (for the sake of her child's life), King Solomon realizes that the latter is the mother. Obviously, the loss of utility for the mother from a change between states (child death) is much larger than the loss, conditional on the child being alive, from a transfer of custody. Given the emotional loss associated with the child death, this would be true no matter how miserable the life of the child could be (conditional on survival). Similarly, there are large differences between lawsuit awards given for wrongful deaths of children and awards given for wrongful births (due to contraceptive failures). Awards for wrongful births are low and mostly based on the costs of raising a child, while awards for wrongful deaths are typically extremely high, at values near our monetary measure of emotional loss (see Zelizer, 1994). This pattern 
supports the idea that the utility cost of losing an existing child is indeed very different from the marginal cost of acquiring an additional child (which is directly related to the marginal benefit of an additional child), even when replacement through additional births is possible.

In our calibrated model, child survival dominates any concern about welfare of children conditional on survival. Therefore, our state-dependent formulation is entirely consistent with the views expressed in the examples above. Also from this perspective, the theoretical setup suggested here seems to be a promising benchmark for the incorporation of altruism and fertility-and therefore future generations-in the evaluation of public policies.

\section{A Appendix: Calibration of $\alpha, \phi$ and $M_{c}$}

Define the "value of a statistical life" as the willingness to pay for a one-shot unit reduction of the probability of death at some specific age (as Murphy and Topel, 2003), without any similar change for future generations. This definition is in line with the empirical interpretation of the "value of a statistical life" and also with the data typically used to estimate this number. Suppose that, for both adult and child mortalities, we are considering decisions when adults are about to realize their fertility choices (age $\tau$, which is closest from the perspective of the model to adults that are raising children). From equations 9 and 10, the "values of a statistical life" for adults and children are given by, respectively:

$$
\begin{aligned}
V S L_{\tau}^{A} & =\left(\frac{1}{\varepsilon_{c}}-1\right) c \int_{\tau}^{\infty} S(t, \tau) d t+\left(b+p_{c} e\right)\left(\frac{1}{\varepsilon_{n}}-1\right) n_{T}, \text { and } \\
V S L_{\tau}^{C} & =\frac{1}{p_{c}}\left\{b n_{T}+\frac{(1-\phi)}{2+(1-\phi)^{2} \mu^{2}}\left(b+p_{c} e\right)+\frac{\alpha p_{c} M_{c}}{u_{c}(c(t))} n_{T}\right\} .
\end{aligned}
$$

With estimates of the "values of a statistical life" for adults and children, the expressions for $V S L_{\tau}^{A}$ and $V S L_{\tau}^{C}$ above define a system of two non-linear equations on $\alpha, \phi$, and $M_{c}$. First order conditions for $c_{t}$ and $n_{T}$ define a third equation, given by

$$
\alpha\left\{\frac{\partial \mathbf{E}\left[N_{T}^{\phi}\right]}{\partial n_{T}} V_{T+1}-M_{c}\left(1-p_{c}\right)\right\}=\left(b+e p_{c}\right) u_{c}\left(c_{t}\right) .
$$

In a stationary environment, $V_{T+1}$ can be substituted by the closed form solution for the constant steady-state value function. Together with the two equations for $V S L_{\tau}^{A}$ and $V S L_{\tau}^{C}$, this expression defines a system of three non-linear equations on three unknowns $\left(\alpha, \phi\right.$ and $\left.M_{c}\right)$.

Blomquist, Miller, and Levy (1996), Mount et al. (2000), and Jenkins, Owens, and Wiggins (2001) present estimates for $V S L_{\tau}^{A}$ and $V S L_{\tau}^{C}$ for the mid-1990's (see Table 1). The other variables 
used in the calibration are set to their 1995 values. Additional parameters, functional forms, and sources of variables used are discussed in the text. The solution to this problem for each different set of estimates of $V S L_{\tau}^{A}$ and $V S L_{\tau}^{C}$ generates the values of $\alpha, \phi$, and $M_{c}$ presented in Table 1.

\section{References}

Arthur, W. Brian (1981). The Economics of Risks of Life. American Economic Review, 71(1), $54-64$.

Becker, Gary S. and Robert Barro (1988). A Reformulation of the Economic Theory of Fertility. Quarterly Journal of Economics, 103(1), 1-25.

Becker, Gary S. and Julio Elias (2006). Introducing Incentives in the Market for Live and Cadaveric Organ Donations, Mimeo, University of Chicago.

Becker, Gary S. and Kevin Murphy (1988). The Family and the State. Journal of Law and Economics, 31(1), 1-18.

Becker, Gary S., Tomas J. Philipson, and Rodrigo R. Soares (2005). The Quantity and Quality of Life and the Evolution of World Inequality. American Economic Review, 95(1), $277-291$.

Bergstrom, Theodore (1982). When Is a Man's Life Worth More Than His Human Capital? In: M. W. Jones-Lee (ed). The Value of Life and Safety. Amsterdam, North-Holland, 3-26.

Bergstrom, Theodore (2006). Benefit-cost in a Benevolent Society. American Economic Review, 96(1), 339-351.

Blomquist, Glenn C., Ted R. Miller and David T. Levy (1996). Values of Risk Reduction Implied by Motorist Use of Protection Equipment: New Evidence from Different Populations. Journal of Transport Economics and Policy, 30(January), 55-66.

Carlin, Paul S. and Robert Sandy (1991). Estimating the Implicit Value of a Young Child's Life. Southern Economic Journal, 85(1), 186-202.

Cropper, Maureen L., Sema K. Aydede, and Paul R. Portney (1992). Rates of Time Preference for Saving Lives. American Economic Review Papers and Proceedings, 82(2), 469-472.

Cropper, Maureen L. and Frances G. Sussman (1988). Families and the Economics of Risks to Life. American Economic Review, 78(1), 255-260.

Deaton, Angus (2004). Health in an Age of Globalization. Brookings Trade Forum 2004, 83-130.

Dickie, Mark and Victoria Ulery (2001). Valuing Health in the Household: Are Kids Worth More than Parents?. Unpublished Manuscript, Association of Environmental and Resource Economists 2001 Workshop.

Garrett, Allison M. (2001). Health Improvements and the National Income and Product Accounts: 1880 to 1940. Ph.D. Dissertation, University of Chicago.

Jenkins, Robin R., Nicole Owens, and Lanelle B. Wiggins (2001). Valuing Reduced Risks to Children: The Case of Bicycle Safety Helmets. Contemporary Economic Policy, 19(4), 397-408. 
Jones-Lee, M. W. (1992). Paternalistic Altruism and the Value of a Statistical Life. Economic Journal, 102(January), 80-90.

Kalemli-Ozcan, Sebnem (2002). Does Mortality Decline Promote Economic Growth? Journal of Economic Growth, 7(4), 411-439.

Lino, Mark (2001). USDA's Expenditure on Children by Families Project: Uses and Changes Over Time. Family Economics and Nutrition Review, 13(1), 81-86.

Mount, Timothy, Weifeng Weng, and William Schulze (2000). Automobile Safety and the Value of Statistical Life in the Family: Valuing Reduced Risk for Children, Adults and the Elderly. United States Environmental Protection Agency Report 0431.

Murphy, Kevin M. and Robert Topel (2003). The Economic Value of Medical Research. In: Kevin M. Murphy and Robert Topel (eds). Measuring the Gains from Medical Research: An Economic Approach. Chicago, University of Chicago Press, 41-73.

Nordhaus, William D. (2003). The Health of Nations: The Contribution of Improved Health to Living Standards. In: Kevin M. Murphy and Robert Topel (eds). Measuring the Gains from Medical Research: An Economic Approach. Chicago, University of Chicago Press, 9-40.

Philipson, Tomas J. and Rodrigo R. Soares (2005). The Economic Cost of AIDS in SubSaharan Africa: A Reassessment. In: Guillem López-Casasnovas, Berta Rivera, and Luis Currais (eds). Health and Economic Growth: Findings and Policy Implications, Cambridge, MIT Press, 313-336.

Preston, Samuel H. (1993). Health Indices as a Guide Principle to Health Sector Planning: A Demographic Critique. In: James N. Gribble and Samuel H. Preston (eds). The Epidemiological Transition - Policy and Planning Implications for Developing Countries. National Academy Press, Washington DC, 126-144.

Rosen, Sherwin (1988). The Value of Changes in Life Expectancy. Journal of Risk and Uncertainty, 1(3), 285-304.

Rosen, Sherwin (1994). The Quantity and Quality of Life: A Conceptual Framework. In: George Tolley, Donald Kendel, and Robert Fabian (eds). Valuating Health for Policy: An Economic Approach. Chicago, University of Chicago Press, 221-248.

Sah, Raaj (1991). The Effects of Child Mortality Changes on Fertility Choice and Parental Welfare. Journal of Political Economy, 99(3), 582-606.

Schelling, Thomas C. (1968). The Life You Save May Be Your Own. In: Samuel B. Chase, Jr. (ed). Problems in Public Expenditure Analysis. Brookings Institution, Washington, D.C., $127-161$.

Soares, Rodrigo, R. (2006). The Welfare Cost of Violence Across Countries. Journal of Health Economics, 25(5), 821-846.

Usher, Dan (1973). An Imputation of the Measure of Economic Growth for Changes in Life Expectancy. In: Milton Moss (ed). The Measurement of Economic and Social Performance, Studies in Income and Wealth, Vol. 38. Conference on Research in Income and Wealth. New York, National Bureau of Economic Research and Columbia University Press, 193-225.

Viscusi, Kip (2005). "The Value of Life." Discussion Paper No. 517, Harvard Law School. 
Wolpin, Kenneth I. (1997). Determinants and Consequences of the Mortality and Health of Infants and Children. In: Mark R. Rosenzweig and Oded Stark (eds). Handbook of Population and Family Economics, Amsterdam, North Holland, 483-557.

Zelizer, Viviana A. (1994). Pricing the Priceless Child: The Changing Social Value of Children. Princeton, Princeton University Press. 